\title{
Risk factors for early onset elevated intraocular pressure after pterygium surgery
}

This article was published in the following Dove Press journal: Clinical Ophthalmology

\author{
Kevin Wu \\ Hyunjoo J Lee \\ Manishi A Desai \\ Department of Ophthalmology, \\ Boston University School of Medicine, \\ Boston Medical Center, Boston, MA, \\ USA
}

Purpose: In this study, we aimed to identify the risk factors for early postoperative elevation of intraocular pressure (IOP) after pterygium surgery.

Patients and methods: All patients in this retrospective cohort study were evaluated for inclusion from a single tertiary care center at Boston Medical Center. Their pre- and postoperative IOP measurements (day 1 , week 1 , month 1 , month 3 , and when clinically necessary) were compared. Patients with postoperative IOP measurement of $>22 \mathrm{mmHg}$ or with an increase in IOP by $\geq 10 \mathrm{mmHg}$ compared with the preoperative measurement value were grouped as "Ocular Hypertension" group; otherwise, patients were grouped in the "No Ocular Hypertension" group. Age, sex, race, baseline IOP, cup-to-disc (C/D) ratio, history of glaucoma, and frequency of use of postoperative steroid drops in all patients were compared. Chi square test was performed to compare the categorical variables, whereas Student's $t$-test was performed to compare continuous variables. We performed a multivariate logistic regression analysis of categorical data with a significance level of $p<0.05$.

Results: In total, 240 patient charts were reviewed for inclusion in this study. Twenty-six patients required pterygium surgery on both eyes; for these patients, the eye with higher IOP was analyzed. Two patients were discontinued from this study because of elevated IOP in the contralateral, nonsurgical eye. Forty-eight out of 212 eyes (22.64\%) developed postsurgical elevation of IOP within the first 3 months of operation. No significant differences were found between age, sex, baseline IOP, C/D ratio, history of glaucoma diagnoses, and frequency of use of postoperative steroid drops. However, Hispanic/Latino race $(p=0.036)$ and lack of application of steroid ointment ( $p=0.001$ ) were found to be the significant risk factors for the development of "Ocular Hypertension" in multivariate analysis.

Conclusion: Early elevation of IOP is a risk of pterygium surgery. One nonmodifiable risk factor, Hispanic/Latino race, and one modifiable risk factor, lack of application of steroid ointments, were identified as potential causes of early postoperative IOP elevation.

Keywords: race, ocular hypertension, postoperative care, steroid, intraocular pressure

\section{Introduction}

Pterygium is a common fibrovascular proliferative disease exhibiting prominent vascularity that originates from the limbal conjunctiva and grows toward the cornea. ${ }^{1}$ Its etiology is not completely understood, but some possible risk factors include older age, decreasing geographical latitude, and male sex. ${ }^{2}$ Treatment options for pterygium range from conservative management with artificial tears and topical steroids to multiple methods of surgical excision when the visual axis is threatened.

Intraocular pressure (IOP) remains the only modifiable risk factor for the development and progression of glaucoma. ${ }^{3}$ After cataract surgery, IOP may increase during the postoperative period. The elevation in IOP is undesirable, particularly if the patient 
has a history of glaucoma., ${ }^{4,5}$ Similarly, early elevation in IOP after pterygium surgery, which is not fully explained by steroid response alone, has been noted in previous studies and at our institution. ${ }^{6}$ While Kuryan et al, identified a significant elevation in IOP after pterygium surgery, they did not find any identifiable risk factors. ${ }^{6}$ Therefore, in this study, we aimed to identify the potential risk factors for the elevation in IOP beyond what have been previously reported, namely, race, given our high number of Hispanic patients, as well as different methods of use of postoperative steroids. Although the elevation in IOP has been found to be short-term and is controllable with pressure-lowering medications, it can remain significantly elevated, which makes it difficult to control during the postoperative period for many patients. ${ }^{7-9}$

\section{Materials and methods}

\section{Patient selection and data collection}

This is a single center retrospective cohort study that evaluated all patient charts with a pterygium removal surgery between April 10, 2014 and June 8, 2017 at a tertiary care center, Boston Medical Center, Boston, MA, USA. A single examiner performed chart review after approval by the Boston University Medical Center Institutional Review Board (H-35567). Given the retrospective nature of this study, patient consent was waived as this study does not pose greater than minimal risk to study subjects. All patient data was deidentified, coded, and limited to research personnel for patient confidentiality. The following inclusion criteria were applied: age $\geq 18$ years, at least one postoperative follow-up visit at Boston Medical Center, and one documented preoperative IOP measurement within normal limits (10-22 mmHg). Patients with undiagnosed ocular hypertension as defined by the elevated IOP of the contralateral eye after surgery were excluded from the study. A total of 240 surgeries from 214 patients were reviewed for inclusion in this study.

Data collected from patient charts included date of surgery, date of follow-up visits, IOP of surgical and nonsurgical eyes, cup-to-disc (C/D) ratio of surgical and nonsurgical eyes, frequency of use of postoperative steroid drops, length of steroid use, past ocular history, race, age, and sex. Race was determined by the patient's self-identified race as documented in the patient's electronic medical record (EMR). Haitian-Creole ethnicity was stratified into the African race for this study. ${ }^{10}$ In addition, an assumption that the patient's self-identified race was their sole race was also made.

\section{Intraocular pressure measurements}

Clinically significant postoperative elevation of IOP was defined as a Goldmann or Tonopen reading of $>22 \mathrm{mmHg}$ or an increase of IOP by $\geq 10 \mathrm{mmHg}$ from baseline IOP. Eyes with clinically significant postoperative elevation in IOP were grouped in the "Ocular Hypertension" group, and all other eyes were grouped in the "No Ocular Hypertension" group. In this study, IOP measurements recorded by the technicians were used unless a clinically significant IOP was recorded, in which case a resident or attending clinician's measurement value was used. Patients who had elevated IOP of the nonsurgical eye with an equal or greater value than that of the surgical eye were defined as the undiagnosed ocular hypertension and therefore were excluded from statistical analysis.

\section{Postoperative care}

Six different primary surgeons performed the pterygium removal surgery of all 240 eyes using fibrin glue with a conjunctival autograft or an amniotic membrane graft. Postoperatively, all patients were administered with topical antibiotic, steroid drops, and anesthetic. These medications were adjusted as clinically necessary. In patients with significantly elevated IOP, topical glaucoma medications were started in accordance with the clinical need. For all patients post operative steroid regimen consisted of either high frequency ( 6 times per day) or low frequency (4 times per day). Additional steroid treatment included subconjunctival dexamethasone injection, neomycin-polymyxin-dexamethasone $3.5 \mathrm{mg} / \mathrm{g}-10,000 \mathrm{unit} / \mathrm{g}-0.1 \%$ ointment, or both. Patients were scheduled for postoperative follow-up visits on day 1 , week 1 , month 1 , and month 3 after surgery. Some patients required additional or extended follow-up visits when clinically necessary, and some patients missed their follow-up visits.

\section{Statistical analysis}

In case of patients who required pterygium surgery on both eyes, the eye with the higher postoperative IOP was included for the statistical analysis. No patients required two pterygium surgeries for recurrence during the timeframe of this study. In addition, the data of patients who did not identify their race were not included in the statistical analysis for race and for multivariate logistic regression analysis. Statistics were calculated using the Statistical Package for the Social Sciences 24.0 for Macintosh (SPSS, Chicago, IL, USA). Continuous data were expressed as mean $\pm \mathrm{SD}$ and compared using Student's $t$-test. Categorical data was expressed as the number for each category and compared using the chi square test $\left(\chi^{2}\right)$. All categorical risk factors were subjected to multivariate logistic regression analysis. All graphs were prepared 
using GraphPad Prism 7 software (GraphPad, La Jolla, CA, USA). Tests required a significance level of $p<0.05$.

\section{Results}

\section{Patient characteristics}

A total of 240 pterygium surgeries were reviewed. Twentysix patients required pterygium surgeries on both eyes, in which case only the postoperative eye with higher IOP was analyzed. Data of two patients were removed from analysis because of the postoperative elevation in IOP in the nonsurgical eye, which we defined as ocular hypertension secondary to steroid response. Thus, a total of 212 surgeries were included in the analysis. Of these, $46(21.7 \%)$ patients had glaucoma-related diagnoses consisting of 38 (17.9\%) patients with suspected glaucoma, $3(1.4 \%)$ primary patients with open-angle glaucoma (POAG), 2 (0.9\%) patients with pseudoexfoliation syndrome, $2(0.9 \%)$ patients with suspected closed-angle glaucoma status-post laser peripheral iridotomy, and $1(0.4 \%)$ patient with normal tension glaucoma.

Overall, patient characteristics included a mean age of $50.38 \pm 14.59$ years, majority being males $52.8 \%$ (112/212), baseline IOP of $14.34 \pm 2.88 \mathrm{mmHg}$, and $\mathrm{C} / \mathrm{D}$ ratio of $0.333 \pm 0.153$ (Table 1 ). A total of $48(22.6 \%)$ patients were included in the "Ocular Hypertension" group. This group had an average age of $48.67 \pm 15.60$ years, baseline IOP of $14.83 \pm 2.86 \mathrm{mmHg}$, and $\mathrm{C} / \mathrm{D}$ ratio of $0.357 \pm 0.173$. There was no statistically significant difference between these values in the "Ocular Hypertension" group compared with the 164 patients in the "No Ocular Hypertension" group, which showed an average age of $50.89 \pm 14.30$ years $(p=0.355)$, baseline IOP of $14.20 \pm 2.88 \mathrm{mmHg}(p=0.177)$, and C/D ratio of $0.326 \pm 0.147(p=0.242)$. Compared to the "No Ocular Hypertension" group, in the "Ocular Hypertension" group, there was a slight but insignificant higher score for male sex $(50.6 \%(83 / 164)$ vs $60.4 \%(29 / 48), p=0.231)$, preexisting glaucoma-related diagnoses $(19.5 \%(32 / 164)$ vs $29.2 \%(14 / 48), p=0.154)$, and high frequency of use of postoperative steroid drops $(23.9 \%(39 / 164)$ vs $29.2 \%$ (14/48), $p=0.489)$.

Patients' self-identified races were Caucasian (21 [10.1\%]), African (55 [26.4\%]), Hispanic (114 [54.8\%]), Asian (17 [8.2\%]), and Arabic (1 [0.5\%]) (Table 2). Incidence rates of developing elevated IOP differed significantly between Caucasians and non-Caucasians (1/21 [4.8\%] vs 45/187 [24.1\%], $p=0.043)$. This was not true for other races, that is, African $(11 / 46,23.9 \%)$ vs non-African $(35 / 162$, $21.6 \%, p=0.659)$, Hispanic $(30 / 114,26.3 \%)$ vs non-Hispanic $(16 / 94,17.0 \%, p=0.107)$, or Asian $(4 / 17,23.5 \%)$ vs nonAsians (42/191, 22.0\%, $p=0.883)$. Compared to Caucasians, Hispanic race had a significantly different incidence rate $(p=0.031)$, which was not seen in African or Asian races $(p=0.103,0.063)$.

\section{Postoperative IOPs}

When comparing the baseline vs postoperative day 1 IOP values (Figure 1), we found a statistically significant increase among all the studied races. Average IOP increased from $14.6 \pm 3.1 \mathrm{mmHg}$ to $16.9 \pm 4.3 \mathrm{mmHg}$ in Africans $(p<0.01)$ from $14.3 \pm 2.8 \mathrm{mmHg}$ to $17.6 \pm 6.0 \mathrm{mmHg}$ in Asians $(p=0.03)$, from $14.4 \pm 2.5 \mathrm{mmHg}$ to $15.9 \pm 3.3 \mathrm{mmHg}$ in Caucasians ( $p=0.03$ ), and from $14.3 \pm 2.9 \mathrm{mmHg}$ to $18.0 \pm$ $4.8 \mathrm{mmHg}$ in Hispanics $(p<0.01)$. A statistically significant increase was also found in case of African and Hispanic race between baseline vs postoperative week 1 IOP values with averages of $17.3 \pm 4.1 \mathrm{mmHg}(p<0.01)$ and $17.8 \pm 5.7 \mathrm{mmHg}$ $(p<0.01)$, respectively.

Among the 48 patients with postoperative elevated IOP, patients first developed clinically significant elevated IOP on an average of $9.42 \pm 16.20$ days postsurgery. Of these 48 patients, $29(60.4 \%)$ patients had elevated IOP identified on postoperative day $1,11(22.9 \%)$ patients on postoperative week 1 (between 6 and 15 days), 7 (14.6\%) patients on postoperative month 1 (between 22 and 44 days), and 1 (2.1\%) patient on postoperative month 3 (83 days) (Figure 2).

Table I Characteristics risk factors of patients for the development of elevated IOP

\begin{tabular}{|c|c|c|c|c|}
\hline & $\begin{array}{l}\text { All cases (eyes) } \\
(N=2 \mid 2)\end{array}$ & $\begin{array}{l}\text { Cases with ocular } \\
\text { hypertension }(N=48)\end{array}$ & $\begin{array}{l}\text { Cases with no ocular } \\
\text { hypertension }(N=164)\end{array}$ & $p$-value \\
\hline Age $\pm S D$ & $50.38 \pm 14.59$ & $48.67 \pm 15.60$ & $50.89 \pm 14.30$ & $0.355^{\mathrm{a}}$ \\
\hline Sex, male (\%) & I I 2 (52.8) & $29(60.4)$ & $83(50.6)$ & $0.23 \mathrm{I}^{\mathrm{b}}$ \\
\hline History of glaucoma (\%) & $46(2 \mid .7)$ & $14(29.2)$ & $32(19.5)$ & $0.154^{\mathrm{b}}$ \\
\hline Baseline IOP $\pm S D$ & $14.34 \pm 2.88$ & $14.83 \pm 2.86$ & $14.20 \pm 2.88$ & $0.177^{a}$ \\
\hline $\mathrm{C} / \mathrm{D}$ ratio $\pm \mathrm{SD}$ & $0.333 \pm 0.153$ & $0.357 \pm 0.173$ & $0.326 \pm 0.147$ & $0.242^{\mathrm{a}}$ \\
\hline Frequency of steroid used, higher frequency (\%) & $52(24.5)$ & $13(27.1)$ & $39(23.8)$ & $0.489^{b}$ \\
\hline
\end{tabular}

Notes: a'Student's $t$-test. ' $C$ hi square test. Age, baseline IOP, and C/D ratio were compared with Student's t-tests and showed no significant difference between ocular hypertension and no ocular hypertension groups. Sex, history of glaucoma related diagnoses, and frequency of prednisolone acetate I\% drops use where compared with Chi square test and no significant differences were found.

Abbreviations: IOP, intraocular pressure; C/D, cup-to-disc. 
Table 2 Racial risk factors for development of elevated IOP

\begin{tabular}{|c|c|c|c|c|c|}
\hline Race & $\begin{array}{l}\text { All cases, } \\
N=208(\%)\end{array}$ & $\begin{array}{l}\text { Cases with ocular } \\
\text { hypertension, } N=46(\%)\end{array}$ & $\begin{array}{l}\text { Cases with no ocular } \\
\text { hypertension, } N=162(\%)\end{array}$ & $\begin{array}{l}p \text {-value (race } \\
\text { vs non-race) }\end{array}$ & $\begin{array}{l}p \text {-value (race } \\
\text { vs Caucasian) }\end{array}$ \\
\hline Caucasian & $21(10.1)$ & I (2.2) & $20(12.3)$ & $0.043 *$ & (Reference) \\
\hline African & $55(26.4)$ & II (23.9) & $44(27.2)$ & 0.659 & 0.103 \\
\hline Hispanic & II 4 (54.8) & $30(65.2)$ & $84(51.9)$ & 0.107 & $0.031 *$ \\
\hline Asian & $17(8.2)$ & $4(8.7)$ & $13(8.0)$ & 0.883 & 0.089 \\
\hline Arabic & I $(0.5)$ & $0(0.0)$ & I $(0.6)^{\prime}$ & - & - \\
\hline
\end{tabular}

Notes: *Results with an asterisk are statistically significant. Chi square tests were used to compare racial risk factors for development of elevated IOP. Statistical analysis showed that Caucasians have a decreased incidence of developing elevated IOP compared to African, Hispanic, Asian, and Arabic races combined $(p=0.043)$. When comparing individual races to Caucasian race, only Hispanic race was found to have a significantly increased risk of postoperative elevated IOP $(p=0.03 \mathrm{I}$ ).

Abbreviation: IOP, intraocular pressure.

Figure 3 shows the Kaplan-Meier survival curves for the time to the elevation of IOP by race. The probability of elevation of IOP at postoperative day 1 was $10.91 \%$ for Africans, $23.53 \%$ for Asians, $0 \%$ for Caucasians, and $15.79 \%$ for Hispanics. At week 1 (7 days) postoperative follow-up visit, the probabilities were $10.91 \%$ for Africans, $23.53 \%$ for Asians, to $3.70 \%$ for Caucasians, and $17.62 \%$ for Hispanics. At month 1 (31 days) postoperative follow-up visit, the probabilities were found to be $16.61 \%$ for Africans, $23.53 \%$ for Asians, $5.00 \%$ for Caucasians, and $23.68 \%$ for Hispanics. Probabilities of increased IOP were unchanged for Caucasians and Asians at 3 months' follow-up visit (92 days), but increased to 34.78\% for Africans and $28.69 \%$ for Hispanics.

\section{Postoperative subconjunctival injection or steroid ointment}

In addition to topical prednisolone acetate $1 \%$ drops, all patients were treated with either perioperative subconjunctival injection of dexamethasone ("Subconjunctival Injection" group), topical neomycin-polymyxin-dexamethasone ointment ("Ointment" group), or both injection and ointment ("Both" group). Twelve patients were in the "Subconjunctival Injection" group and 7 out of 12 (58.33\%) developed "Ocular Hypertension". This is compared to 25 out of 105 (23.81\%) patients in the "Ointment" group and 17 out of 108 (15.74\%) treated with both (Table 3). Using the "Both" group as the reference category, a statistically significant increase

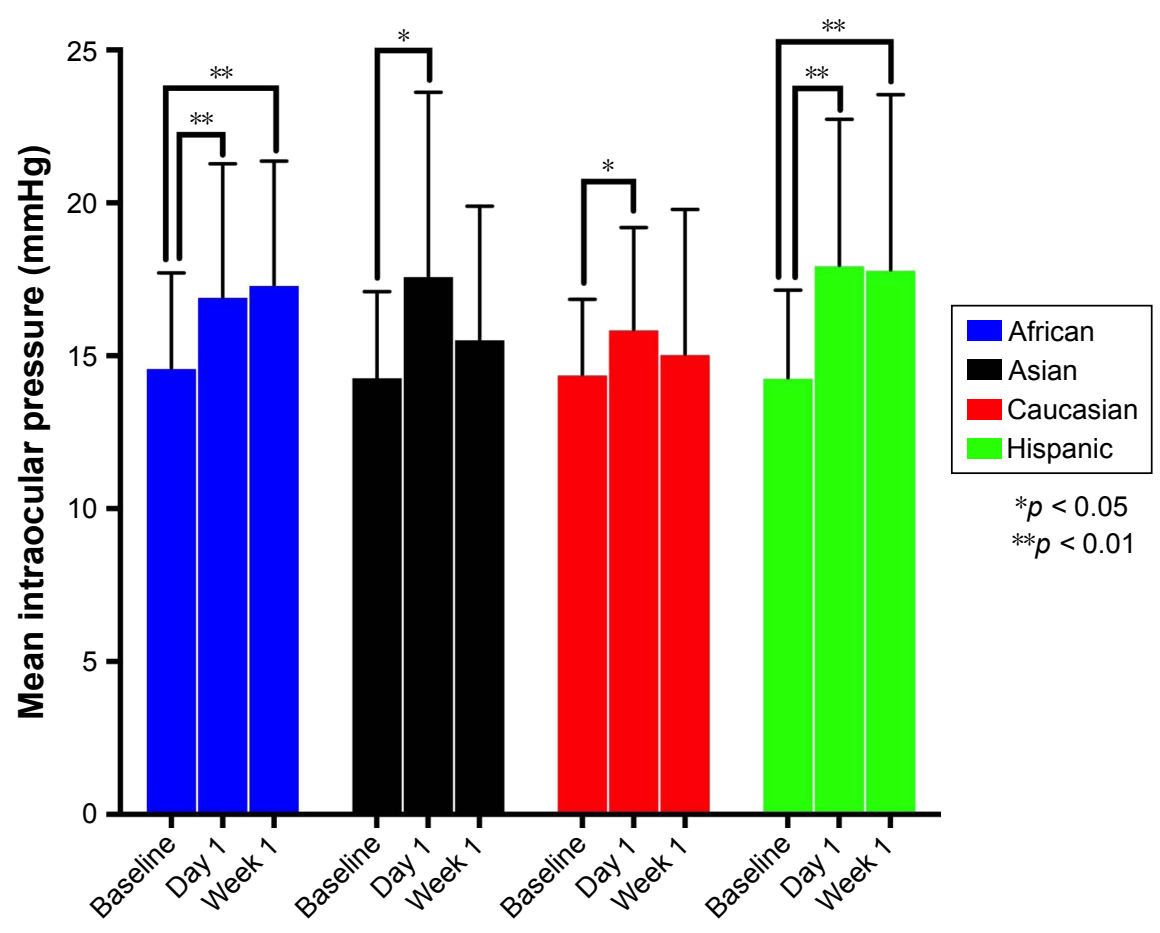

Figure I Postoperative IOP compared to baseline by race. Only postoperative day I and week I were included as more follow-up visits were missed starting at month I. Paired $t$-tests showed a significant difference in IOP from baseline at postoperative day I for all races. Postoperative week I was significantly elevated from baseline for African and Hispanic races only.

Abbreviation: IOP, intraocular pressure. 


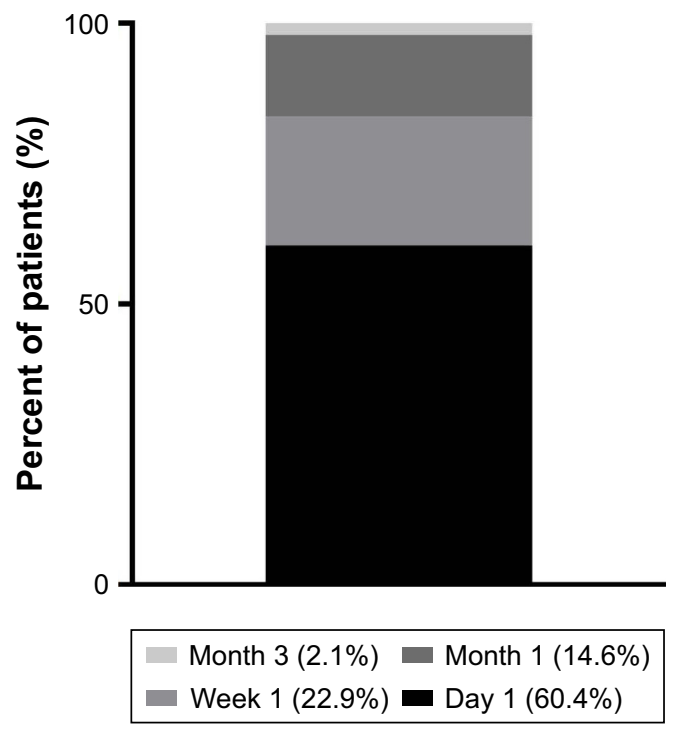

Figure 2 Time of first recorded elevated IOP. Percent of when all patients first developed elevated IOP. The majority of cases in the "Ocular Hypertension" group were first found to have elevated IOP was at their day I postoperative appointment (60.4\%).

Abbreviation: IOP, intraocular pressure. in percentage of patients developing "Ocular Hypertension" occurred in patients treated with only subconjunctival injection $(p=0.001)$. We did not find any difference between the "Ointment" and "Both" groups $(p=0.223)$.

\section{Multivariate analysis}

In univariate analysis, Hispanic race was associated with increased incidence of "Ocular Hypertension" during the postoperative period ( $p=0.031$ ) (Table 2$)$. In multivariate analysis, Hispanic race (OR $=9.845,95 \%$ confidence interval $[\mathrm{CI}]=1.157-83.741)$ was also associated with an increased risk of postoperative ocular hypertension ( $p=$ 0.036) (Table 4). African (OR $=6.361,95 \% \mathrm{CI}=0.694$ 58.329) and Asian ( $\mathrm{OR}=8.976,95 \% \mathrm{CI}=0.802-100.461)$ races were not found to be a significant risk factor in univariate (Table 2 ) or multivariate analysis ( $p=0.102,0.075)$ (Table 4). The "Subconjunctival Injection" group carried a significantly higher risk of development of ocular hypertension in univariate $(p=0.001)$ (Table 3$)$ and multivariate

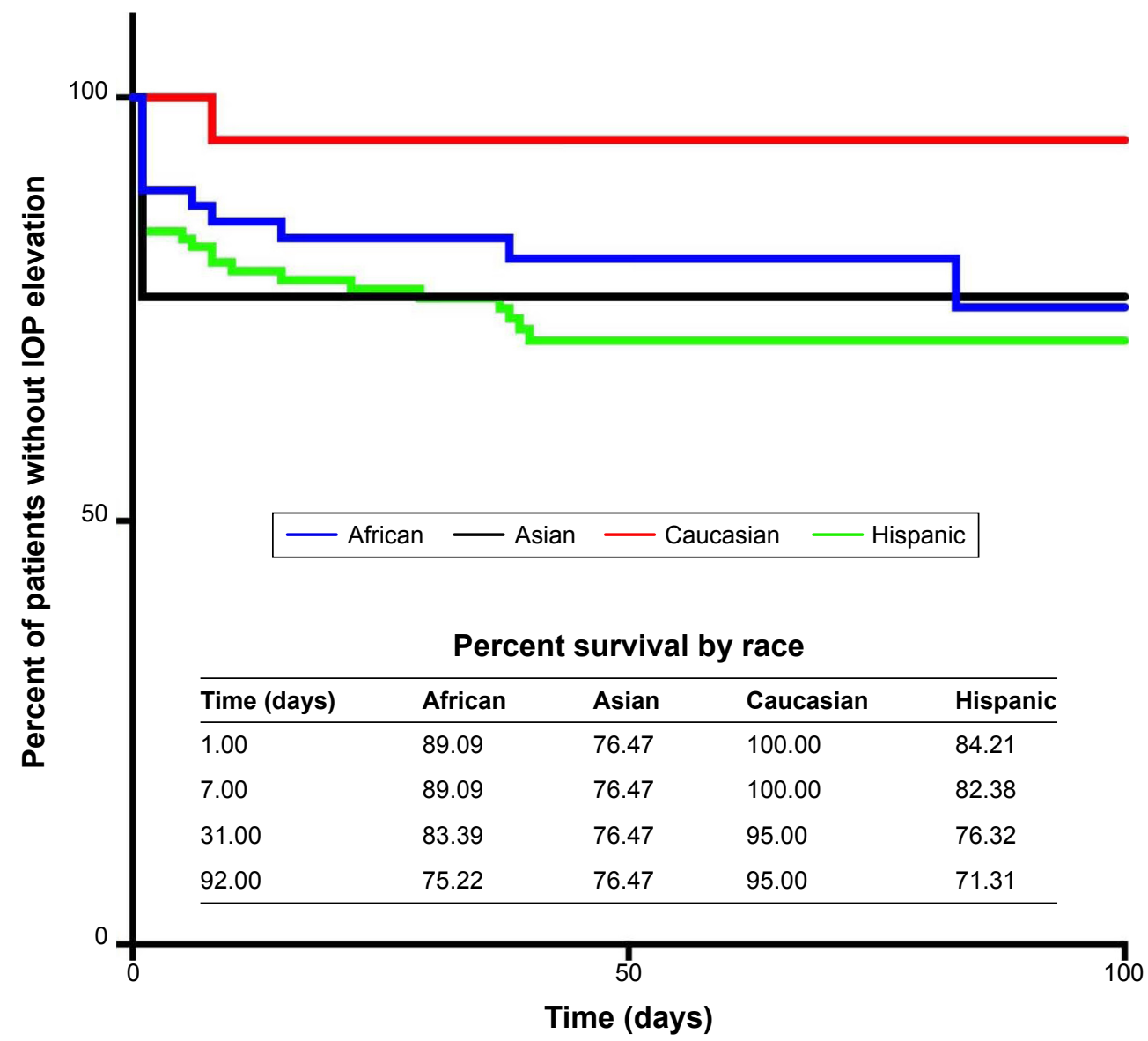

Figure 3 Kaplan-Meier survival curve for time to development of elevated IOP between African, Asian, Caucasian, and Hispanic races. Time was limited to I00 days as the last patient developed elevated IOP at 3 month postoperative appointment. Table shows the percent survival for each race at day I, week I, month I, and month 3 postoperative visits.

Abbreviation: IOP, intraocular pressure. 
Table 3 Postoperative topical ointment vs subconjunctival steroid injection

\begin{tabular}{llll}
\hline Type of steroid & $\begin{array}{l}\text { Cases with } \\
\text { ocular } \\
\text { hypertension (\%) }\end{array}$ & $\begin{array}{l}\text { Cases with } \\
\text { no ocular } \\
\text { hypertension (\%) }\end{array}$ & p-value \\
\hline $\begin{array}{l}\text { Subconjunctival } \\
\text { injection }\end{array}$ & $7(58.33)$ & $5(41.67)$ & $0.00 I^{*}$ \\
$\begin{array}{l}\text { Ointment } \\
\text { Both }\end{array}$ & $25(23.8 I)$ & $80(76.19)$ & 0.223 \\
\hline
\end{tabular}

Notes: *Results with an asterisk are statistically significant. Subconjunctival injection of dexamethasone without topical ointment experienced a significantly increased incidence of ocular hypertension compared to use of both subconjunctival injection with neomycin-polymyxin B-dexamethasone ointment. Occurrences of ocular hypertension after treatment with topical ointment, subconjunctival injection, or both were compared with a chi square test using both steroid treatment options as the reference.

analysis $(\mathrm{OR}=6.627,95 \% \mathrm{CI}=1.615-27.189, p=0.009)$ (Table 4). Male sex also had higher rates of elevated IOP (OR $=1.241,95 \% \mathrm{CI}=0.602-2.560)$ but was not significant $(p=0.559)$. In addition, no significant risks were found with a positive history of glaucoma $(\mathrm{OR}=1.614,95 \% \mathrm{CI}=$ $0.725-3.593, p=0.241$ ) or with higher frequency of use of topical prednisolone acetate $1 \%$ drops $(\mathrm{OR}=1.367,95 \% \mathrm{CI}=$ $0.542-3.448, p=0.936)$.

\section{Discussion}

Elevated IOP can be a serious complication after pterygium surgery. Our study evaluated the incidence and risk factors of elevated IOP postpterygium surgery after removing potential cases of undiagnosed ocular hypertension. We found that the percentage occurrence of postoperative ocular hypertension was high (22.64\%), which is in line with the findings of other studies. ${ }^{6,11}$

Topical steroids can induce ocular hypertension over the course of weeks. ${ }^{12}$ According to Turalba et al, steroid-induced ocular hypertension was found to be at a rate of $2.97 \%$ after the surgery of photorefractive keratectomy. ${ }^{13}$ Lorenz et al and Laurell et al reported a rate of $0-4.8 \%$ after cataract surgery. ${ }^{14,15}$ In this study, we found $21.28 \%$ rate of elevated IOP, which is much greater than that of other surgeries of anterior segment. ${ }^{13-15}$ We believe that the majority of cases of elevated IOP in this study were due to pterygium surgery and not due to the steroid-induced ocular hypertension; this distinction, however, is difficult to ascertain with complete certainty. The majority (29/48) of elevated IOP cases were measured on postoperative day 1 , sooner than the expected steroid response. Furthermore, we noticed that additional steroid use in the form of ointment and subconjunctival injection had fewer rates of elevated IOP (Table 3). Another potential source of error is the effect of early epithelial defect after pterygium surgery on Goldmann applanation tonometer measurements. The timing of the postoperative day 1 epithelial defect coincides with the elevation of IOP observed in this study. ${ }^{16}$ However, this is likely not attributable to our study as irregular mires prompted the use of a Tonopen and would not explain the elevation in IOP in postoperative week 1 or month 1.

Table 4 Multivariate adjusted odds ratio for the development of elevated IOP

\begin{tabular}{|c|c|c|c|c|}
\hline & $\begin{array}{l}\text { Number in ocular } \\
\text { hypertension group/total }\end{array}$ & $\begin{array}{l}\text { Incidence } \\
\text { rate (\%) }\end{array}$ & $\begin{array}{l}\text { Multivariate adjusted } \\
\text { odds ratio }(95 \% \mathrm{Cl})\end{array}$ & $p$-value \\
\hline \multicolumn{5}{|l|}{ Sex } \\
\hline Female & $18 / 99$ & 18.18 & (Reference) & - \\
\hline Male & $32 / 109$ & 29.36 & I.24I $(0.602,2.560)$ & 0.559 \\
\hline \multicolumn{5}{|l|}{ History of glaucoma } \\
\hline No & $38 / 163$ & 23.31 & (Reference) & - \\
\hline Yes & $12 / 45$ & 26.67 & I.6I4 $(0.725,3.593)$ & $0.24 I$ \\
\hline \multicolumn{5}{|l|}{ Frequency of steroid used } \\
\hline Lower & $36 / 162$ & 22.22 & (Reference) & - \\
\hline Higher & $14 / 46$ & 30.43 & I.367 $(0.542,3.448)$ & 0.936 \\
\hline \multicolumn{5}{|c|}{ Type of postoperative steroid use } \\
\hline Both & $17 / 93$ & 18.28 & (Reference) & - \\
\hline Topical ointment & $27 / 104$ & 25.96 & $1.306(0.568,3.004)$ & 0.529 \\
\hline Subconjunctival injection & $6 / 11$ & 54.54 & $6.627(1.615,27.189)$ & $0.009 *$ \\
\hline \multicolumn{5}{|l|}{ Race } \\
\hline Caucasian & $|/ 2|$ & 4.76 & (Reference) & - \\
\hline African & $10 / 55$ & 18.18 & $6.361(0.694,58.329)$ & 0.102 \\
\hline Hispanic & $35 / 114$ & 30.70 & $9.845(I .157,83.74 I)$ & $0.036 *$ \\
\hline Asian & $4 / 17$ & 23.53 & $8.976(0.802,100.46 \mid)$ & 0.075 \\
\hline
\end{tabular}

Notes: *Results with an asterisk are statistically significant. When adjusted for sex, glaucoma history, frequency of steroid use, and ethnicity, use of subconjunctival injection was a significant risk factor for development of ocular hypertension $(p=0.005)$. In addition, Hispanics had a significantly increased risk of developing elevated IOP compared to Caucasians when adjusted for the above characteristics. 
A possible explanation for the effects of pterygium surgery on IOP is its effects on corneal biomechanics. Pterygium leads to alterations of the anterior stroma, Bowman's membrane, and the epithelial layer of the cornea. ${ }^{17}$ Two groups of researchers have reported that corneal hysteresis $(\mathrm{CH})$, the cornea's ability to absorb pressure by bending, decreased after pterygium surgery compared to healthy controls during the first postoperative month. ${ }^{18,19}$ Low $\mathrm{CH}$ was also found to be associated with elevated IOP in patients with glaucoma and additionally correlated with visual field progression and optic disc surface compliance. ${ }^{20,21}$ It is possible that during the brief postoperative period, the effects of pterygium surgery prevented the cornea from bending and absorbing pressure exerted from aqueous humor, causing a transiently elevated IOP.

Another possible explanation for the elevated IOP after pterygium surgery is the effect of extraocular surgery on downstream drainage of aqueous humor. In the conventional trabecular meshwork drainage pathway, aqueous humor drains from Schlemm's canal to the aqueous vein and then into the episcleral and conjunctival veins. After removal of these downstream channels in pterygium surgery, it is possible that the residual episcleral and conjunctival veins were adjusting to the relative overloading of aqueous humor. This is similar to the elevation of IOP seen after extensive conjunctival removal in a previous case report. ${ }^{22}$ In case of pterygium surgery, however, fewer conjunctivas were removed in this study, which may account for the transient instead of permanent elevation of IOP.

In this study, multivariate analysis identified Hispanic race as a strong risk factor for postoperative IOP spikes (Table 3). Genetic factors play a role in the pathogenesis of primary open-angle glaucoma, such as its determinants on IOP, C/D ratio, and central corneal thickness. A genome-wide association study has shown that these factors are highly heritable, vary according to race, and likely involve multiple polymorphisms. ${ }^{23}$ Recently, a study performed on Hispanic population identified WNT7B as one locus, likely among many, that is associated with central corneal thickness. ${ }^{24}$ Differences in genetic factors among racial groups may cause varying degree of responses after pterygium surgery.

In addition to Hispanic race, there is reason to suspect that other races have increased risk of elevated IOP. African race is a risk factor for the development of POAG, and our study showed a significant increase in IOP at week 1 postoperative visit (Figure 1). ${ }^{23,25}$ Future studies with higher power may discover a significant risk for pterygium surgery-induced elevation of IOP in this group of patients.
The fact that patient demographics plays a significant role in the elevation of IOP after pterygium surgery raises interesting questions on its role in screening patients and their postoperative care. Our study shows that Hispanic race, and possibly African race, is a risk factor. While pterygium surgeries are relatively benign, we found that $22.64 \%$ of the patients develop elevated IOP; thus, these risk factors should be taken into consideration during screening. The importance of and potential need for more postoperative follow-up visits should be explained to patients with higher risk of suffering negative consequences of elevated IOP. While glaucoma-related diagnoses were not found to be a risk factor, preoperatively careful consideration for surgery and more regular follow-up visits is especially true for patients with glaucoma as elevated IOP can be even more problematic in this group of patients. The potential need for glaucoma management should also be discussed. Fourteen patients in this study required an addition of 1 glaucoma medication, 2 patients required an addition of 2 glaucoma medications, and 1 patient required an addition of 3 glaucoma medications. No patients required laser or surgery for management of IOP.

Differences between the rates of postoperative IOP elevation were also seen in certain types of steroid use. While all patients were prescribed prednisolone acetate 1\% drops ophthalmic suspension, patients were additionally treated with either intraoperative subconjunctival dexamethasone injection and/or postoperative dexamethasone-containing ointment. Subconjunctival injection was associated with the highest rate of postoperative "Ocular Hypertension" at a rate of $58.33 \%$, followed by the use of topical steroid ointment at a rate of $23.81 \%$. Use of both methods combined had the lowest risk at a rate of $16.84 \%$. Timing of steroid ointment use (immediately after the case or after postoperative day 1 ) did not significantly affect the development of "Ocular Hypertension". One explanation for this trend is that inflammation of the cornea contributes to the elevation in IOP. Use of topical loteprednol etabonate results in low aqueous humor concentration and decreases mean IOP by $1-2 \mathrm{mmHg}$ after pterygium surgery relative to other corticosteroids. ${ }^{26,27}$ Loteprednol etabonate concentrations are also the highest in the cornea. ${ }^{23}$ Topical steroid preparations might be able to treat inflammation better at this site than that of periocular preparations and a combination of these two might be synergistically useful in decreasing corneal inflammation.

Our study is also of interest because of our unique patient population. The National Institutes of Health (NIH) fiscal report documented that $8.4 \%$ of the domestic enrollment in NIH-funded clinical research were of Hispanic race in 2012, 
which came down from a rate of $8.6 \%$ in $2011 .^{28}$ While reviews found mixed results of Hispanic population as a risk factor for POAG, we were clearly able to define an association between Hispanic race and ocular hypertension after pterygium surgery given our large Hispanic population. ${ }^{23}$

This study had some limitations, which include the inherent biases in retrospective studies, including a nonrepresentative sample size and nonblinded chart reviews, among others. Furthermore, the primary objective of this study was to evaluate Hispanic race as a risk factor for the development of ocular hypertension, which accounted for $59.6 \%$ of the entire patient population at Boston Medical Center undergoing pterygium surgery. Thus, the power of this study was too low to significantly evaluate other demographic factors such as African or Asian race, which accounted for only 20.4 and $8.1 \%$, respectively. Many follow-up visits were also missed by patients. While this was accounted for with censored times in the Kaplan-Meier survival curve (Figure 3), other tables and figures likely underrepresent the number of cases in the “Ocular Hypertension” group. In addition, slight variations in surgical approach could also be a confounding factor. As previously stated, the power of this study is an additional limitation. A larger sample size might help to identify additional risk factors, and future studies should attempt to identify these risk factors into power calculations. Finally, given the retrospective nature of this study, a nonstandardized protocol of IOP measurement introduced additional biases. Multiple technicians and residents measured the IOP in addition to the use of both Goldmann Aplannation Tonometery and Tonopen. We believe that these methods do not detract from our results. Albeit Tonopen provides slightly overestimated readings. Previous studies found a nonsignificant difference between Goldmann Aplannation Tonometery and Tonopen measurements. ${ }^{29,30}$

\section{Conclusion}

Ocular hypertension after pterygium surgery is a common complication, and Hispanic race is a risk factor. It is possible that patients will require glaucoma medications after surgery to control their IOP, and Hispanic patients should be provided diligent preoperative screening and postoperative follow-up visits to prevent complications of prolonged elevated IOP. In addition, we found that the use of topical steroid ointments was associated with lower rates of ocular hypertension than that of steroid drops.

While other races were not found to be a significant risk factor in multivariate analysis, the original design of this study was to evaluate Hispanic race. It is likely that other races, such as African and Asian, are also risk factors for the development of ocular hypertension as was seen in univariate analysis. Future studies should include a larger population to observe additional risk factors. Patient age, baseline IOP, history of glaucoma-related diagnoses, $\mathrm{C} / \mathrm{D}$ ratio, and frequency of use of topical steroid drops were not found to impact risk of developing ocular hypertension than that of a steroid injection.

\section{Disclosure}

The authors report no conflicts of interest in this work.

\section{References}

1. Robert B, Ronald B, George H, et al. Ophthalmic pathology and intraocular tumors. In: Louis C, Christopher R, George C, editors. Basic and Clinical Science Course. San Francisco, CA: American Academy of Ophthalmology; 2014:56-58.

2. Liu L, Wu J, Geng J, Yuan Z, Huang D. Geographical prevalence and risk factors for pterygium: a systematic review and meta-analysis. $B M J$ Open. 2013;3(11):e003787.

3. [No authors listed] Comparison of glaucomatous progression between untreated patients with normal-tension glaucoma and patients with therapeutically reduced intraocular pressures. Collaborative Normal-Tension Glaucoma Study Group. Am J Ophthalmol. 1998;126(4):487-497.

4. Turalba A, Payal AR, Gonzalez-Gonzalez LA, et al. Cataract surgery outcomes in glaucomatous eyes: results from the veterans affairs ophthalmic surgery outcomes data project. Am J Ophthalmol. 2015; 160(4):693.e1-701.e1.

5. Chen PP, Lin SC, Junk AK, Radhakrishnan S, Singh K, Chen TC. The effect of phacoemulsification on intraocular pressure in glaucoma patients: a report by the American Academy of Ophthalmology. Ophthalmology. 2015;122(7):1294-1307.

6. Kuryan JT, Rosenberg J, Madu A. Risk factors for elevated intraocular pressure after pterygium excision. Invest Ophthalmol Vis Sci. 2009;50(13):903.

7. Musch DC, Gillespie BW, Niziol LM, Lichter PR, Varma R; CIGTS Study Group. Intraocular pressure control and long-term visual field loss in the collaborative initial glaucoma treatment study. Ophthalmology. 2011;118(9):1766-1773.

8. Slabaugh MA, Bojikian KD, Moore DB, Chen PP. Risk factors for acute postoperative intraocular pressure elevation after phacoemulsification in glaucoma patients. J Cataract Refract Surg. 2014;40(4):538-544.

9. Zohdy GA, Rogers ZA, Lukaris A, Sells M, Roberts-Harry TJ. A comparison of the effectiveness of dorzolamide and acetazolamide in preventing post-operative intraocular pressure rise following phacoemulsification surgery. J R Coll Surg Edinb. 1998;43(5):344-346.

10. CIA.gov. The World Factbook: HAITI. [updated July 27, 2017]. Available from: www.cia.gov/library/publications/the-world-factbook/geos/ ha.html\#. Accessed August 6, 2017.

11. Husain M, Nguyen A, Nagi K. Ocular hypertension profile after pterygium excision. Invest Ophthalmol Vis Sci. 2013;54(15):5629.

12. Pleyer U, Ursell PG, Rama P. Intraocular pressure effects of common topical steroids for post-cataract inflammation: are they all the same? Ophthalmol Ther. 2013;2(2):55-72.

13. Busool Y, Mimouni M, Vainer I, et al. Risk factors predicting steroidinduced ocular hypertension after photorefractive keratectomy. J Cataract Refract Surg. 2017;43(3):389-393.

14. Lorenz K, Dick B, Jehkul A, Auffahrt GU. Inflammatory response after phacoemulsification treated with $0.5 \%$ prednisolone acetate or vehicle. Graefes Arch Clin Exp Ophthalmol. 2008;246(11):1617-1622.

15. Laurell CG, Zetterström C. Effects of dexamethasone, diclofenac, or placebo on the inflammatory response after cataract surgery. $\mathrm{Br} J$ Ophthalmol. 2002;86(12):1380-1384. 
16. Kocatürk T, Gençgönül A, Balica F, Özbağcivan M, Çakmak H. Combined eye gel containing sodium hyaluronate and xanthan gum for the treatment of the corneal epithelial defect after pterygium surgery. Clin Ophthalmol. 2015;9:1463-1466.

17. Dushku N, Jhon MK, Schultz GS, Reid TW. Pterygia pathogenesis: corneal invasion by matrix metalloproteinase expressing altered limbal epithelial basal cells. Arch Ophthalmol. 2001;119(5):695-706.

18. Koç M, Yavrum F, Uzel MM, Aydemir E, Özülken K, Yılmazbaş P. The effect of pterygium and pterygium surgery on corneal biomechanics. Semin Ophthalmol. 2018;33(4):449-453.

19. Gros-Otero J, Pérez-Rico C, Montes-Mollón MA, Gutiérrez-Ortiz C, Benítez-Herreros J, Teus M. Effects of pterygium on the biomechanical properties of the cornea: a pilot study. Arch Soc Esp Oftalmol. 2013; 88(4):134-138.

20. Medeiros FA, Meira-Freitas D, Lisboa R, Kuang TM, Zangwill LM, Weinreb RN. Corneal hysteresis as a risk factor for glaucoma progression: a prospective longitudinal study. Ophthalmol. 2013;120(8): 1533-1540.

21. Congdon NG, Broman AT, Bandeen-Roche K, Grover D, Quigley HA. Central corneal thickness and corneal hysteresis associated with glaucoma damage. Am J Ophthalmol. 2006;141(5):868-875.

22. Lee YR, Na JH, Kim JY, Sung KR. Increased intraocular pressure after extensive conjunctival removal: a case report. Korean J Ophthalmol. 2013;27(2):141-144.

23. Abu-Amero K, Kondkar AA, Chalam KV. An updated review on the genetics of primary open angle glaucoma. Int J Mol Sci. 2015;16(12): 28886-28911.
24. Gao X, Nannini DR, Corrao K, et al; International Glaucoma Genetics Consortium. Genome-wide association study identifies WNT7B as a novel locus for central corneal thickness in Latinos. Hum Mol Genet. 2016;25(22):5035-5045.

25. Tielsch JM, Sommer A, Katz J, Royall RM, Quigley HA, Javitt J. Racial variations in the prevalence of primary open-angle glaucoma. The Baltimore Eye Survey. JAMA. 1991;266(3):369-374.

26. Comstock TL, Decory HH. Advances in corticosteroid therapy for ocular inflammation: loteprednol etabonate. Int J Inflam. 2012;2012: 789623.

27. Awan MA, Agarwal PK, Watson DG, McGhee CN, Dutton GN. Penetration of topical and subconjunctival corticosteroids into human aqueous humour and its therapeutic significance. Br J Ophthalmol. 2009;93(6):708-713.

29. National Institutes of Health. Monitoring Adherence to the NIH Policy on the Inclusion of Women and Minorities as Subjects in Clinical Research Fiscal Year 2011-2012. Available from: https://orwh.od.nih. gov/resources/pdf/Inclusion-ComprehensiveReport-FY-2011-2012.pdf. Accessed August 9, 2017.

29. Yilmaz I, Altan C, Aygit ED, et al. Comparison of three methods of tonometry in normal subjects: Goldmann applanation tonometer, non-contact airpuff tonometer, and Tono-Pen XL. Clin Ophthalmol. 2014;8:1069-1074.

30. Galgauskas S, Strupaite R, Strelkauskaite E, Asoklis R. Comparison of intraocular pressure measurements with different contact tonometers in young healthy persons. Int J Ophthalmol. 2016;9(1):76-80.
Clinical Ophthalmology

\section{Publish your work in this journal}

Clinical Ophthalmology is an international, peer-reviewed journa covering all subspecialties within ophthalmology. Key topics include: Optometry; Visual science; Pharmacology and drug therapy in eye diseases; Basic Sciences; Primary and Secondary eye care; Patien Safety and Quality of Care Improvements. This journal is indexed on

Submit your manuscript here: http://www.dovepress.com/clinical-ophthalmology-journal

\section{Dovepress}

PubMed Central and CAS, and is the official journal of The Society of Clinical Ophthalmology (SCO). The manuscript management system is completely online and includes a very quick and fair peer-review system, which is all easy to use. Visit http://www.dovepress.com/ testimonials.php to read real quotes from published authors. 